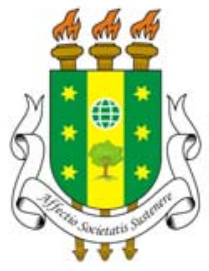

educationis

Journal homepage:

www.arvore.org.br/seer

\section{EDUCAÇÃO FÍSICA E SEXUALIDADE: UM ESTUDO DE CASO EM ESCOLAS PÚBLICAS DE ARACAJU, SERGIPE}

\section{RESUMO}

Procurou-se identificar como os profissionais da educação física estão trabalhando o tema transversal orientação sexual na escola, bem como compreender a relação entre a sexualidade e a educação física escolar. Indagamos então, como a educação física escolar poderá contribuir com a discussão acerca das questões ligadas a sexualidade dos adolescentes. A importância desse tema surge a partir do momento em que ele vem tendo grande destaque no meio social, então se procurou observar o posicionamento da educação física quanto a esse tema. Esse estudo se caracteriza por uma pesquisa descritiva, onde foi utilizados questionários para coleta de dados, o estudo foi aplicados em 03 (três) escolas publicas de Aracaju com alunos do $1^{\circ}$ ao $3^{\circ}$ ano do Ensino Médio. No resultado da analise dos dados foram abordadas questões relacionadas à discriminação nas de educação física onde se observou uma maior ocorrência de discriminação por parte dos homens; foi investigado também sobre a presença do tema sexualidade nas aulas de educação física, obteve um resultado preocupante, já que a grande parte das ocorrências apontou a ausência do tema nas aulas; foi feita uma analise quanto aos conteúdos utilizados nas aulas de educação física, onde observou-se ainda a supremacia dos esportes, sendo vôlei mais aplicados para meninas e o futsal para os meninos. Consideramos que a educação física se torna um ambiente propicio a discussão acerca do tema sexualidade, em contrapartida observamos a negligencia dos profissionais quanto a esse tema.

PALAVRAS-CHAVE: Educação Física; Orientação Sexual; Escola.

\section{PHYSICAL EDUCATION AND SEXUALITY: A CASE STUDY IN PUBLIC SCHOOLS OF ARACAJU, SERGIPE, BRAZIL}

\section{ABSTRACT}

It was looked to identify as the physical education professionals are working about the transversal subject: "sexual orientation at school", as well as to understand the relation between the sexuality and the school physical education. So we inquire, how school physical education will be able to contribute with the quarrel concerning on questions of the teenager's sexuality. The importance of this subject appears from the moment where it comes having great prominence in the social system, so, it was directed to observe the view point of the physical education about this subject. This study is characterized by a descriptive research, where it was used questionnaires to collect the data, it was applied in 03 (three) publish schools of Aracaju, with 1st to 3rd of Second grade teaching students. The result of it analyzes had been boarded questions related to the discrimination in the physical education classes, where it was observed a bigger occurrence of discrimination by the males; sexuality in the physical education lessons was also investigated on the presence of the subject, got a preoccupying result, since the great part of the occurrences pointed the absence of that subject in lessons; was made an analyzes about how much does it content is used at physical education lessons, so, it still observed the supremacy of the sports, where it is being volleyball more applied for girls and the indoor soccer for the boys. We consider that the physical education becomes propitiates site to quarrel concerning about the subject sexuality, on the other way we observe the professionals neglects about this subject.

KEYWORDS: Physical Education; Sexual Orientation; School.
Educationis, Aquidabã, v.1, n.1, Ago, Set, Out, Nov, Dez 2012, Jan 2013.

ISSN 2318-3047

\section{SECTION: Articles}

TOPIC: Práticas Esportivas e de Lazer

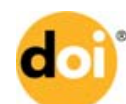

DOI: 10.6008/ESS2318-3047.2013.001.0003

Rafael Rocha Silva

Universidade Tiradentes, Brasil http://lattes.cnpq.br/3956542711437931 rafael rocha3112@hotmail.com

Maria Janaina Marques da Silva Universidade Tiradentes, Brasil http://lattes.cnpq.br/4595891305841969 janaedf@hotmail.com

Received: $12 / 09 / 2012$

Approved: 10/01/2013

Reviewed anonymously in the process of blind peer.

\section{Referencing this:}

SILVA, R. R.; SILVA, M. J. M.. Educação física e sexualidade: um estudo de caso em escolas públicas de Aracaju, Sergipe. Educationis, Aquidabã, v.1, n.1, p.2235, 2013. DOI: http://dx.doi.org/10.6008/ESS23183047.2013.001.0003 


\section{INTRODUÇÃO}

A Educação sexual é um tema de grande repercussão na escola e na sociedade na atualidade, por trazer para o cenário educacional uma temática que discute um dos polêmicos problemas da sociedade a Sexualidade e a formação do sujeito. Neste sentido, sentimos a necessidade da discussão deste tema, ancorado a partir dos Temas Transversais da Educação. "Os temas transversais são alguns dos atuais problemas da sociedade brasileira, onde há certa dificuldade para solucioná-los, motivo que leva a tarefa de tratar desses aspectos para a escola" (DARIDO, 2005, p.85)

Cabe a Educação Física assim como as demais disciplinas curriculares o trato pedagógico com os temas transversais sugeridos pelos Parâmetros Curriculares Nacionais (PCN, 2000). Neste estudo nos deteremos em discutir o tema transversal Orientação Sexual configurado como objeto de estudo.

Ao tratar do tema orientação sexual, busca-se considerar como algo inerente à vida e à saúde, que expressa desde cedo no ser humano, engloba o papel social do homem e da mulher, o respeito por si e pelo outro, as discriminações e os estereótipos atribuídos e vivenciados em seus relacionamentos, o avanço da AIDS e gravidez indesejada na adolescência, entre outros, que são problemas atuais e preocupantes. (PCN’s, 2000, p.107)

Ao perceber que esses problemas de ordem biológica e sócio-cultural, geram uma preocupação para as escolas, já que muitos adolescentes abandonam os estudos para resolver problemas dessa natureza, uma alternativa encontrada foi transformar problemáticas sociais em temas para serem trabalhados transversalmente aos conteúdos tradicionais de cada disciplina que compõe o currículo escolar.

Uma pesquisa realizada pela Fundação Oswaldo Cruz entre julho de 1999 e fevereiro de 2001 mostra que $32,5 \%$ das mães que engravidaram na adolescência estudaram, no máximo, até a quarta série do ensino fundamental. (ALTMANN, 2001, p.1)

As crianças e os adolescentes muitas vezes não têm noção de como se processa o desenvolvimento de sua sexualidade, o que os deixa expostos a situações de constrangimento e perigo, vivem em uma curiosidade constante, demonstrada através de gestos e posicionamentos inadequados apesar de comuns entre eles.

Recentemente a mídia impressa veiculou um escândalo de abuso sexual em rede nacional, protagonizado pela nadadora Joana Maranhão que revelou ter sofrido abuso sexual por parte de seu treinador aos 9 anos de idade. Em uma entrevista a revista Veja Joana falou que

na primeira vez que aconteceu, eu não tinha a menor noção de sexualidade. Muitas coisas passaram por minha cabeça. Será que isso é normal? Será que ele tem o direito de fazer isso? Eu só sabia que era uma coisa que doía, me machucava e não me fazia bem. Eu estava sozinha com ele na piscina. Foi um susto. E Doía. (VEJA, 2008). 
Fica evidente a gravidade da falta de informações sobre sexualidade, estando a escola e a família como responsáveis diretos por instrumentalizar as crianças e adolescente no sentido de minimizar esta condição de desinformação, entretanto, muitas vezes a escola não possui subsídios para realizar uma adequada orientação sobre o assunto.

Desse modo, perguntamos como a Educação Física Escolar poderá contribuir com a discussão acerca das questões ligadas à sexualidade dos adolescentes?

Para este estudo definimos como objetivo identificar como a Educação Física está trabalhando o tema transversal Orientação sexual na escola. Além de compreender a relação entre a sexualidade e a prática da Educação Física.

A Educação Física Escolar por sua peculiaridade de trabalhar com a cultura corporal de movimento, onde o corpo acaba ganhando lugar de destaque, torna-se uma das disciplinas curriculares onde se instalam mecanismos capazes de passar informações coerentes e que estimulem a reflexão crítica sobre o tema.

Torna-se importante a discussão desse tema, a partir do momento em que ele tem sido bastante discutido no meio social, então se procurou observar como a Educação Física está se posicionando quanto ao trato da sexualidade dos alunos.

Esse tema engloba os conceitos de sexualidade ligada a vida e a saúde; às
questões de gênero dando ênfase ao papel social de homens e mulheres e os
estereótipos e preconceitos da relação entre ambos; além das discussões
relacionadas às doenças sexualmente transmissíveis e a gravidez na
adolescência. (DARIDO, 2005, p.93)

Levando em conta que cada vez mais cedo adolescentes tem relação sexual, muitas vezes sem uma devida orientação sobre os riscos causados pela falta de informações (ou má informação), muitas das vezes os pais trabalham, não tendo tempo para conversar e orientar seus filhos; muitos filhos não tem abertura para falar com os pais sobre esse tema, ressaltamos então a importância da participação da escola e neste estudo da Educação Física no esclarecimento dos alunos sobre o tema transversal.

Mais uma vez recorremos ao episodio da nadadora Joana Maranhão, onde a mãe dela confessa que a filha chegou a comentar dos abusos que estava sofrendo, e ela não acreditou, pois imaginava que Joana tava fantasiando (VEJA, 2008).

A escola deverá informar os familiares dos alunos sobre a inclusão de conteúdos de Orientação Sexual na proposta curricular e explicar os princípios norteadores da proposta. O diálogo entre escola e família deverá se dar de todas as formas pertinentes a essa relação. (PCN’s, 2000, p.124)

Esse trabalho por estar ligado diretamente ao papel da Educação Física perante um tema discutido por todos os setores sociais sem discriminação de raça, cor, ou classe social, poderá gerar uma imagem positiva e agradável para todos os profissionais da área, fomentando uma postura social favorável aos profissionais da educação física. 
Sendo a Educação Física a disciplina responsável pela vivência de movimentos, são comuns situações onde há contato corporal, os alunos por estarem em fase de crescimento e desenvolvimento mental e corporal, sentem-se constrangidos com muitas formas de contato perante seu corpo e o do colega.

Utilizamos para a realização deste trabalho uma cuidadosa revisão de literatura voltada para este contexto, bem como pesquisa de campo onde procuramos identificar os aspectos ligados as expressões dos adolescentes sobre sexualidade e Educação Física.

Esse trabalho é composto por uma introdução; breve revisão de literatura composta de temas relacionados ao gênero e sociedade, a importância da educação física na orientação sexual e a sexualidade na adolescência; a metodologia aplicada para a realização da pesquisa, e a analise e discussão dos resultados obtidos, seguindo de uma conclusão onde abordaremos os resultados de nosso problema e objetivos. Os temas serão tratados de forma clara e concisa, para que proporcione uma leitura agradável e reflexiva.

\section{METODOLOGIA}

Esse estudo está caracterizado como uma pesquisa descritiva, segundo GIL (2007, p. 42), "as pesquisas descritivas tem como objetivo primordial a descrição das características de determinada população ou fenômeno". Já sobre a pesquisa exploratória, GIL $(2007$, p. 41) diz que: "tem como objetivo proporcionar maior familiaridade com o problema, com vistas a torná-lo mais explicito ou a construir hipóteses".

Para coleta de dados serão utilizados questionários com perguntas abertas, uma vez que representa "um instrumento de investigação que visa recolher informações baseando-se, geralmente, na inquisição de um grupo representativo da população em estudo." (AMARO, 2005, p.3).

Para se chegar à população investigada, adotamos alguns procedimentos metodológicos, inicialmente foi feito um levantamento bibliográfico sobre o tema por meio de artigos, teses, dissertações e livros, em seguida foi feito uma aproximação do campo de estudo a partir de um levantamento das escolas públicas estaduais da cidade de Aracaju que ofertam Educação Física escolar para o ensino médio, sendo que a seleção dessas escolas obedeceu a critérios pré estabelecidos como: escolas de grande porte, escolas que tenham um caráter tradicional e acessibilidade.

O universo da pesquisa se constituiu por três escolas púbicas estaduais totalizando 10\% do total existente. A amostra elaborada para esse estudo, sendo composta por 135 alunos das escolas selecionadas e alunos do $1^{\circ}$ ao $3^{\circ}$ ano do ensino médio que participam regularmente das aulas de Educação Física. 


\section{REVISÃO TEÓRICA}

\section{Gênero e Sociedade}

Frequentemente a problemática sexualidade, conflitos de gênero e discriminação possuem formações aquém das competências da escola, ou seja, o problema vem sendo formulado e enraizado pela própria sociedade, não isolando nem isentando a escola de toda e qualquer culpa a que venha ter, mas colocar a competência exclusivamente na instituição seria um equívoco grave. "Em nosso país, constatamos uma insuficiência de políticas públicas, de programas e ações de saúde e educação que abrangem com exclusividade o estrato populacional que é definido como adolescência e juventude" (CATHARINO, 2005, p.4).

A discussão acerca de gênero vai alem da diferenciação entre homem e mulher, ela pertence aos paradigmas sociais que, assim como os temas já citados, englobam a organização familiar, as identidades e papeis assumidos pelos sujeitos sociais.

A família, que possuía funções produtivas, privatizou-se, construindo-se um mundo "feminino", privado, da casa, que veio a se colocar como oposto ao mundo público, da rua, que se tornou masculino nas práticas, na ideologia e no imaginário social. (VAITSMAN, 2001, p.14)

Gênero foi uma categoria criada pelas mulheres na década de 1980, para começar a demonstrar a discriminação em vários setores como: no político, econômico e social.

Entender as relações de gênero como fundadas em categorizações presentes em toda a ordem social, permite compreender não somente a posição das mulheres, em particular, como subordinada, mas também a relação entre sexualidade e poder. (ANJOS, 2000, p.2)

Se formos ver o lado histórico constatamos que essa questão de discriminação de gênero sempre esteve presente na sociedade, desde seu início até os dias atuais, porém, camuflado sobre diferentes facetas ao longo da história.

Recorrendo a uma reflexão histórica percebemos que até a bem pouco tempo o papel feminino em nossa sociedade limitava-se ao de dona de casa e mãe, não sendo possível à maioria das mulheres alçar vôos para além dessa realidade. (GOMES, 2007, p. 229)

É de estrema importância se pararmos para analisar de onde seria, talvez, a origem de todo o processo, na mídia, na moda, no capitalismo, simplesmente no modo de pensar da população, variáveis bastante abrangentes existem para a questão.

A sociedade, de forma preconceituosa determina as atividades masculinas e femininas. Era instituído para as mulheres cuidar da casa e para o homem o trabalho fora de casa.

No decorrer de todo o século XX presenciamos a mudança do papel feminino de esposa e mãe apenas, para o de esposa, mãe e trabalhadora (em alguns casos ela tem ficado apenas com o de trabalhadora) que busca ascensão em sua carreira e tem alcançado cargos cada vez mais altos, chegando, por vezes, a ser 
chefes de nações, como hoje acontece na Alemanha e no Chile, paises tradicionalmente machistas onde, até bem pouco tempo atrás, pareceria piada se disséssemos que seriam governados por uma mulher. (GOMES, 2007, p. 230)

Em busca de se imporem na sociedade as mulheres procuram áreas de trabalho, por exemplo: o curso de pedagogia, a maioria são mulheres, tem poucos homens e os que tem muitas as vezes surgem comentários, colocando em falso a sua masculinidade. "Nessa época de capitalismo e globalização, onde a disputa entre gênero ultrapassa a barreiras apenas econômicas, é o status social que vem a ser colocado em destaque em nosso sistema social." (AQUINO, et al., 2001, p.21)

\section{A Importância da Educação Física na Orientação Sexual}

A temática da sexualidade gera discussões bastante atuais em nossa sociedade, e é evidente a necessidade da capacitação dos professores para que o tema seja tratado de forma bastante atraente e que as informações sejam bastante reflexivas e que não estimulem nenhuma forma de preconceito.

Segundo os PCN's (2000, p.121), "O trabalho de orientação sexual na escola é entendido como problematizar, levantar questionamentos e ampliar o leque de conhecimentos e de opções para que o aluno, ele próprio, escolha seu caminho".

A discussão sobre sexualidade na escola é bastante delicada, uma vez que envolve alunos estão em fase de crescimento e descoberta e é uma fase de extrema explosão hormonal, além de que as informações devem ser bastante adequadas à faixa etária dos alunos.

O professor deve orientar as questões tratadas pelos alunos, mantendo uma postura crítica de maneira que seus valores não influencie na decisão dos alunos. Para isso é possível utilizar de matérias veiculadas pela mídia dirigidas a adolescentes e que tratem da sexualidade. (DARIDO, 2005, p. 94)

É importante ressaltar que essa discussão não deve se restringir apenas ao ambiente da educação formal, e sim a uma intervenção multidisciplinar, a escola deve trabalhar juntamente com a família, já que a ela também é responsável pela formação integral da criança, e deve tratar de informações pertinentes ao cotidiano da formação do sujeito.

Por entender que a abordagem oferecida acontece a paritr de uma visão pluralista de sexualidade e o papel da escola é abrir espaço para que essa pluralidade de concepções, valores e crenças possa se expressar, não compete a escola, em nenhuma situação, julgar como certa ou errada a educação que cada família oferece. (PCN's, 2000, p. 124)

Podemos observar com freqüência palestras e oficinas sobre orientação sexual no âmbito escolar, essas são ações importantes para o desenvolvimento do sujeito, mas por si só não dão conta da complexidade dos problemas oriundos da sexualidade, assim sendo necessárias ações mais efetivas das escolas, da família e acima de tudo do poder publico. "Também apontamos para a importância de que as propostas pedagógicas não se restrinjam a uma dimensão meramente 
informativa. Com isso não estamos negando a relevância desta dimensão". (CATHARINO, 2005, p.8).

A escola é um dos ambientes responsáveis por estimular no aluno reflexões críticas sobre a sexualidade, estimulação essa que permita que ele mesmo construa seu conhecimento sobre o que é ou não viável.

Os conteúdos tratados na escola devem destacar "a importância da saúde sexual e reprodutiva" e "os cuidados necessários para promovê-la". A escola deve, integrada com serviços públicos de saúde, conscientizar para a importância de ações não só curativas, mas também preventivas, atitudes denominadas como de "autocuidado". Identifica-se aí a intenção de educar alunos e alunas para o autodisciplinamento de sua sexualidade. (ALTMANN, 2001, p.6)

A temática sexualidade, diferentemente das outros temas presentes no planejamento escolar, é bem visível no cotidiano das aulas de Educação Física, a exemplo das relações conflituosas observadas entre meninos e meninas nas aulas mistas, o que muitas vezes leva as meninas a deixam de realizar as atividades, sob o argumento de que a roupa está inadequada para a prática, por achar que não tem um corpo que suas amigas e amigos julgam como bonito.

Além de discussões acerca da construção das diferenças de gênero nas atividades motoras, são abordados temas referentes aos papéis sociais atribuídos a homens e mulheres, aos estereótipos de gênero e à influência da educação na consolidação do masculino e do feminino. (PEREIRA, 2004, p. 15)

Para o adolescente a aceitação em determinado grupo está diretamente relacionada à estética corporal a um biótipo socialmente construído e comum a todos do mesmo grupo. A capacidade de pensar, de desenvolver seu intelectual, não quer dizer que precisam ter um corpo julgado pela sociedade como o corpo bonito. "A sociedade constrói papeis diferenciados para homens e mulheres com base nas diferenças corporais, que são utilizadas para justificar e/ou definir atributos para cada um dos sexos." (PEREIRA, 2004, p.20)

É importante ressaltar que um dos importantes papeis da Educação Física segundo DARIDO (2005, p.94) é "identificar as atitudes preconceituosas, já que as aulas se encontram repletas de situações ligadas ao gênero, ou seja, a construção social e cultural do masculino e do feminino.

Essa situação preconceituosa gera um grave problema de exclusão na escola, e os professores são os responsáveis sobre a discussão sobre questão de gênero, inclusão e respeito ao diferente e a cultura alheia. E o professor de educação física é o responsável por estimular os alunos a conhecer seu próprio corpo e reconhecer sua sexualidade.

Nessa exploração do próprio corpo, na observação do corpo de outros, e a partir das relações familiares é que a criança se descobre num corpo sexuado de menino ou menina. Preocupa-se então mais intensamente com as diferenças entre os sexos, não só as anatômicas, mas também com todas as expressões que caracterizam o homem e a mulher. (PCN's, 2000, p.118) 
O professor de Educação Física deve ter uma visão critica e abrangente do que acontece em suas aulas, assim podendo intervir de maneira inteligente em um momento em que o aluno precise de ajuda quanto a sua sexualidade.

O professor (de Educação Física) é uma referência importante para seus alunos, pois a Educação Física propicia experiência de aprendizagem peculiar ao mobilizar os aspectos afetivos, sociais, éticos e de sexualidade de forma intensa e explícita, o que faz com que o professor de Educação Física tenha um conhecimento abrangente de seus alunos. (ALTMANN, 2001)

A educação física dispõe de várias características para tratar do tema sexualidade, os profissionais tem oportunidades que possibilitam a todo momento incluir nas aulas aspectos que trabalhem o tema de maneira eficaz e que não haja nenhum constrangimento dos alunos em expressar suas curiosidades e seus desejos, facilitando uma orientação eficaz e interessante por parte do professor.

"A aula de educação física é um dos momentos privilegiados da escola, em que os alunos experimentam uma multiplicidade de comportamentos, ao trabalharem sua corporeidade." (PEREIRA, 2004, p. 17)

A disciplina curricular educação física possui vários conteúdos; jogos e brincadeiras, esportes, dança, ginástica e lutas; esses que podem servir de componente interdisciplinar que auxilia no desenvolvimento de projetos e debates relacionados a questão da orientação sexual na escola e na própria aula de educação física. Essas atividades criam possibilidades de maior liberdade para expressar sentimentos e emoções nas aulas.

As atividades que caracterizam as aulas de educação física, as quais se encontram carregadas de linguagens simbólicas advindas da comunicação entre pessoas ao jogar, dançar e lutar, possibilitam experimentar ou expressar afetos e sentimentos, desejos e sedução, e essas sensações podem causar bastante prazer. (DARIDO, 2005, p.94)

\section{Sexualidade na Adolescência}

A adolescência é uma fase de explosão hormonal, onde o indivíduo começa a perceber seu corpo e sua sexualidade, o adolescente desenvolve várias curiosidades e dúvidas, então esta ai a importância do dialogo com os professores, pois estes devem incentivar os jovens a falar suas vontades, dos seus sentimentos e curiosidade, assim diminuindo a ansiedade deles. Já que segundo Rosistolato (s.d., p.3) "os professores precisam estar dispostos a lidar com as emoções dos alunos para que promovam a melhoria dos processos escolares e dos relacionamentos entre docentes e discentes".

Essa necessidade que os adolescentes tem de desabafar, e geralmente não tem a abertura para dialogar em casa com seus pais ou na escola com seus educadores já que se sentem constrangidos, assim eles vão procurar as resposta que necessitam com amigos ou 
pessoas mais experientes, que nem sempre tem condições de orientar corretamente os adolescentes.

Para que o trabalho de Orientação Sexual possa se efetivar de forma coerente com a visão pluralista de sexualidade aqui proposta, é necessário que as diferentes crenças e valores, as dúvidas e os questionamentos sobre os diversos aspectos ligados à sexualidade encontrem espaço para se expressar. (PCN,s, 2000, p. 128)

É nessa fase da puberdade onde o sujeito descobre suas limitações e fraquezas, onde a um desequilíbrio emocional já que esta passando por uma crise de crescimento físico, psíquico e de maturação sexual, eles necessitam de informações trabalhadas detalhadamente por profissionais capazes de debater sobre esse tema com extrema naturalidade e responsabilidade, sem deixar que reste nenhuma duvida e nenhum constrangimento após o debate, isso não ocorrendo, os adolescentes expressam esses sentimentos e curiosidades de forma agressiva.

Os adolescentes expressam sua sexualidade, assim como sua vivencia amorosa, através das roupas que usam, musicas produzidas e consumidas, pela linguagem gestual, pelos movimentos, em esportes praticados ou vivenciados por eles, e até no humor. (CATHARINO, 2005, p.8)

Os educadores devem entender o que se passa com o adolescente nessa fase de transição, sendo um dos papeis da escola e de todas as disciplinas curriculares, criar instrumentos necessários para que os jovens produzam reflexão crítica sobre o que esta acontecendo, e da liberdade para que o adolescente se expresse e acabe com sua ansiedade.

"Professores são vistos como profissionais despreparados para "lidar com essas questões", o que cria relações de dependência com os orientadores sexuais, limita espaços de atuação profissional e justifica a existência da educação sexual na escola. (ROSISTOLATO, s.d., p.5)

\section{RESULTADOS E DISCURSSÃO}

Para o tratamento dos dados coletados com os questionários, optamos pela Análise de Conteúdo, onde segundo Franco (2003), o texto é um meio de expressão do sujeito, onde o analista busca categorizar as unidades temáticas (palavras ou frases) que se repetem, inferindo uma expressão que as representem.

Alguns cuidados são necessários neste tipo de análise, pois transforma o conteúdo das informações em temas e, depois, em categorias. Para classificar os elementos em categorias é preciso identificar o que eles têm em comum, permitindo seu agrupamento. Este tipo de classificação é chamado de análise categorial. 
Tabela 01: Discriminação entre meninos e meninas nas aulas mistas de educação física.

\begin{tabular}{|c|c|c|}
\hline CATEGORIA & SUB-CATEGORIA & $\mathrm{N}^{\circ}$ OCOR. \\
\hline $\begin{array}{l}\text { Percepção das meninas } \\
\text { sobre discriminações nas } \\
\text { aulas de Educação Física } \\
\text { mistas }\end{array}$ & $\begin{array}{l}\text { Sim, alongamento (2) } \\
\text { Sim, discriminação do futsal feminino (5) } \\
\text { Sim, modalidades esportivas (3) } \\
\text { Sim, flexão de pernas (1) } \\
\text { Sim, os meninos se acham superiores (2) } \\
\text { Sim (6) } \\
\text { Não (27) }\end{array}$ & 46 \\
\hline $\begin{array}{l}\text { Percepção dos meninos } \\
\text { sobre discriminações nas } \\
\text { aulas de Educação Física } \\
\text { mistas }\end{array}$ & $\begin{array}{l}\text { Sim (5) } \\
\text { Sim, separando meninos de meninas (1) } \\
\text { Sim, pela aparência do corpo do colega (2) } \\
\text { Sim, as de deitar no colchonete (1) } \\
\text { Sim, queimado (2) } \\
\text { Não (33) }\end{array}$ & 44 \\
\hline $\begin{array}{l}\text { Procedimento do professor } \\
\text { diante de situações de } \\
\text { discriminação }\end{array}$ & $\begin{array}{l}\text { Ele explica muito sobre o corpo humano (2); Ele toma satisfação com a } \\
\text { pessoa e exige respeito com o colega (13); Tenta da apoio moral (6); } \\
\text { Normal (2); Tenta resolver da melhor maneira (2); Pergunta se a pessoa } \\
\text { que perder peso (2); Não fez nada (8); Quando não faz nada, fica só rindo } \\
\text { (1); Trata com desprezo e não de incomoda (1); Finge que não esta vendo } \\
(1) ;\end{array}$ & 38 \\
\hline
\end{tabular}

Fazendo referência a discriminação entre meninos e meninas nas aulas de educação física, foi necessário a elaboração de 3 (três) categorias, a primeira relacionada a percepção das meninas quanto a presença de discriminação nas aulas de educação física, onde 19 ocorrências dizem haver discriminação nas aulas, e 27 ocorrências dizem não existir discriminação nas aulas.

A segunda categoria refere-se a percepção dos meninos quanto a existência de discriminação nas aulas, onde 11 ocorrências dos meninos dizem haver discriminação nas aulas de educação física, enquanto 33 das ocorrências dizem não haver nenhum tipo de discriminação.

Nessas duas categorias temos um número satisfatório de ocorrências que dizem não existir nenhum tipo de discriminação nas aulas de educação física, isso se torna importante para o desenvolvimento moral dos alunos, consequentemente tendo uma boa influencia na formação do sujeito através das aulas de educação física.

O professor de educação física, assim como dos demais componentes curriculares, deve estar sempre preparado para coibir a prática de atividades e atitudes discriminatórias e excludentes, no momento da sua ocorrência, mediante o diálogo. (DARIDO, 2005, p. 91)

Ainda pode-se observar as meninas tem maior percepção de descriminação do que os meninos, apareceram subcategorias relacionadas a discriminação do futsal feminino e também por os meninos se sentirem superiores.

Isto porque a transmissão de valores ancorados historicamente se dá, especialmente, através do convívio social, ou seja, os adultos responsáveis pela educação das crianças repassam o que aprendem dos seus antepassados, e a escola como instituição detentora das funções educacional e de formação social, também é precursora, transmissora e mantenedora de valores, que, por vezes criam desigualdades. (PEREIRA, 2004, p. 4)

Em contraponto, presenciamos um possível nivelamento de valores, quando observamos que homens e mulheres tiveram um numero de ocorrências bem próximo quando se trata de uma negação a existência de discriminação na escola. 
Ainda que o movimento de mulheres nos tenha trazido no século passado, transformações significativas, ainda hoje os espaços e oportunidades sociais se encontram assimétricos para homens e mulheres (CATHARINO, 2005, p.13).

A terceira categoria ressalta os procedimentos metodológicos do professor diante de uma atitude de discriminação em suas aulas, nessa categoria podemos observar através das respostas dos alunos um alto nível de despreparo e ate de desprezo por parte dos profissionais, quando se trata desses acontecimentos de discriminação nas aulas.

Um fator preocupante já que o professor é um dos principais responsáveis pela educação ética e moral dos alunos, e deve ter fundamentos para uma discussão interessante sobre a discriminação quanto a gênero, ou a qualquer outro tipo de discriminação.

"Em relação às questões de gênero, por exemplo, o professor deve transmitir, pela sua conduta, a equidade entre os gêneros e a dignidade de cada um individualmente" (PCN's, 2000, p.124).

Tabela 02: O Tema Transversal orientação Sexual nas aulas de educação Física.

\begin{tabular}{l|l|l}
\hline \multicolumn{1}{c|}{ CATEGORIA } & \multicolumn{1}{c|}{ SUB-CATEGORIA } & $\mathbf{N}^{\circ}$ OCOR. \\
\hline $\begin{array}{l}\text { Presença do Tema } \\
\text { nas aulas de } \\
\text { Educação Física }\end{array}$ & $\begin{array}{l}\text { Sim (5); As vezes (1); Sim, porque é fundamental essa discussão sobre esse } \\
\text { tema inclusive na educação física (1); Sim, com um questionário(1). }\end{array}$ & 8 \\
\hline $\begin{array}{l}\text { Ausência do Tema } \\
\text { nas aulas de } \\
\text { Educação Física }\end{array}$ & $\begin{array}{l}\text { Não (28); Não, mas eu acho necessário, talvez o que agente não escuta em } \\
\text { casa pode discutir com o professor na escola, a liberdade é maior (1); Não, } \\
\text { ainda não (4); Não, e se acontecer os meninos ficam só tirando onda, e não } \\
\text { levam a sério (1); Não, até porque discutimos isso quase todo momento (1); } \\
\text { Não, nunca (2) }\end{array}$ & $\mathbf{3 7}$ \\
\hline
\end{tabular}

Quando foi feito referencia a existência do tema transversal orientação sexual, foi necessário criar 2 (duas) categorias; a primeira referente a presença do tema nas aulas de educação física, esse teve 8 ocorrências; e a segunda relacionada a ausência do tema nas aulas, com 37 ocorrências.

Temos aqui um resultado preocupante, já que observamos um grande nível de ocorrências relacionadas a ausência do assunto nas aulas de educação física, com esse resultado voltamos ao ponto sobre a importância da discussão do tema transversal orientação sexual, os adolescentes necessitam de uma intervenção pedagógica que crie possibilidades para organizar debates inerentes ao esclarecimento de seus desejos, duvidas e curiosidades.

A escola deve, integrada com serviços públicos de saúde, conscientizar para a importância de ações não só curativas, mas também preventivas, atitudes denominadas como de "autocuidado". Identifica-se aí a intenção de educar alunos e alunas para o autodisciplinamento de sua sexualidade. (ALTMANN, 2001, p.6)

Faz parte do currículo de todos os professores os temas transversais, é responsabilidade e dever de todo educador transmitir informações e criar diálogo pertinente ao tema transversal sexualidade, em pleno século $X X I$ é inadmissível que os professores sejam omissos quando se trata desse tema.

É necessário então que o educador tenha acesso à formação especifica para tratar de sexualidade com crianças e jovens na escola, possibilitando a construção 
de uma postura profissional e consciente do trato desse tema. (PCN's, 2000, p.123)

Tabela 03: Os conteúdos das aulas de educação Física no ensino médio.

\begin{tabular}{l|l|l}
\hline CATEGORIA & SUB-CATEGORIA & $\mathbf{N}^{\circ}$ OCOR. \\
\hline $\begin{array}{l}\text { Opinião dos alunos sobre os } \\
\text { conteúdos voltados para os } \\
\text { meninos }\end{array}$ & Futsal (18); Vôlei (2); Handebol (1); Basquete (4); musculação (1) & 26 \\
\hline $\begin{array}{l}\text { Opinião dos alunos sobre os } \\
\text { conteúdos voltados para as } \\
\text { meninas }\end{array}$ & $\begin{array}{l}\text { Vôlei (14); Handebol (2); Esportes Individuais (1); Queimado (1); } \\
\text { caminhada (2); Calistenia (2); yoga (1) }\end{array}$ & 23 \\
\hline $\begin{array}{l}\text { Opinião dos alunos sobre os } \\
\text { conteúdos voltados para } \\
\text { ambos os sexos }\end{array}$ & Futsal (3); Vôlei (3); Handebol (1); Queimado: Mistas (1) & 8 \\
\hline $\begin{array}{l}\text { Conteúdos específicos para } \\
\text { meninos e meninas }\end{array}$ & $\begin{array}{l}\text { - Não (28) } \\
\text { - As aulas devem ser aplicadas independente do sexo (1) } \\
\text { - Não, são todas iguais (3) } \\
\text { - Não, são as mesmas (1) } \\
\text { - Não,todos exerć́cios são para o mesmo sexo (1) } \\
\text { - Não, porque é interessante. (1) } \\
\text { - Ate hoje não vi nenhuma (2) }\end{array}$ & 41 \\
\hline
\end{tabular}

Referente aos conteúdos da educação física na escola, foram criadas 4 (quatro) categorias, a primeira relacionada aos conteúdos voltados para os meninos, com 26 ocorrências, e encontramos um grande número de ocorrência na sub-categoria futsal com 18 das ocorrências.

A segunda refere-se aos conteúdos voltados as meninas, com 23 ocorrências, sendo a subcategoria vôlei com maior número com 14 ocorrências.

A terceira foi a opinião dos alunos quanto a aplicação dos conteúdos para ambos os sexos, que teve 8 ocorrências, sendo que as principais sub-categorias foi o futsal e o vôlei, com 3 ocorrências cada um.

A quarta foi relacionada a existência de conteúdos específicos para meninos e para meninas, com 41 ocorrências, onde 28 dos alunos diz não existir nenhuma atividade especifica para meninos e para meninas.

Podemos perceber ainda hoje a supremacia dos esportes nas aulas de educação física, em especial ressalta-se o aparecimento do futsal e o vôlei, como os principais esportes praticados na escola. Isso mostra a ausência da diversidade cultural e da falta de vivencia dos alunos nas aulas de educação física.

$\mathrm{Na}$ atualidade, os esportes coletivos são os que mais despertem interesse na população, como é o caso mais popular deles: o futebol. Esse interesse pronunciado nos esportes coletivos se reflete nas próprias aulas de educação física escolar no Brasil. (DARIDO, 2005, p. 182)

É notável a percepção de um numero considerável de alunos que dizem existir aulas separadas nas aulas de educação física, é de extrema importância que as aulas sejam mistas em vários momentos da educação física, a importância da sociabilização, do desenvolvimento da sexualidade dos alunos, depende da interação entre eles, meninos e meninas. 
Segundo Oliveira (1996, p.121), as aulas mistas possuem um maior potencial de sociabilização entre os alunos, porem, pode não garantir efetivamente um relacionamento satisfatório entre os alunos.

Mas é evidente a diferença do comportamento motor entre meninos e meninas, isso se reflete na preferência de meninos e meninas por esportes específicos para cada um dos sexos, já que as meninas preferem atividades mais suaves e os meninos atividades mas movimentadas. "Não é possível negar as diferenças biológicas entre os sexos, porém o meio sociocultural deve ser considerado, em especial no que diz respeito à distribuição de poder." (PEREIRA, 2004, p.3)

\section{CONCLUSÕES}

Concluímos que as aulas de educação física se tornam um ambiente propicio a prática pedagógica relacionada a discussão sobre o tema transversal orientação sexual, em contrapartida observamos que o tema sexualidade pouco tem sido debatido pelos professores de educação física, um resultado preocupante já que os adolescentes estão cada vez mas atentos quando se trata da sexualidade, e se não encontram esse debate na escola ou na família, as informações ficaram restritas a grupos de amigos, pátios e festas.

Foi possível observar discriminação de gênero quando se trata de conteúdos e abordagens nas aulas de educação física, é necessário então que os profissionais criem projetos curriculares que permitam a inclusão de gênero na educação física como um todo.

A educação física tem as mais importantes ferramentas para trabalhar a orientação sexual na escola de forma eficaz e interessante, essa é o momento onde se faz necessário que os professores de educação física faça valer sua formação, e deixar a transparecer sua importância pedagógica e social através da eficiência na formação integral dos nossos alunos.

\section{REFERÊNCIAS}

AQUINO, E. M. L.; HEILBORN, M. L.; KNAUTH, D.; BOZON, M.; ALMEIDA, M. C.; ARAÚJO, J.; MENEZES, G.. Adolescência e reprodução no Brasil: a heterogeneidade dos perfis sociais. Caderno Saúde Pública, Rio de Janeiro, v.19, sup.2, p.S377-S388, 2003.

ALTMANN, H.. Orientação sexual nos parâmetros curriculares nacionais. Estudos Feministas, Florianópolis, v.9, n.2, p.576, 2001.

AMARO, A.; PÓVOA, A.; MACEDO, L.. A arte de fazer questionários. Porto: Universidade do Porto, 2005.

ANACLETO, J.. Gênero: que história é essa? A mulher brasileira nos espaços público e privado. São Paulo: Perseu Abramo, 2004.

ANJOS, G.. Identidade sexual e identidade de gênero: subversões e permanências. Sociologias, Porto Alegre, v.2, n.4, p.274-305, 2000.

BRASIL. Parâmetros curriculares nacionais: pluralidade cultural: orientação. 2 ed. Rio de Janeiro: DP\&A, 2000. 
CATHARINO, T. R.. Gênero e sexualidade no espaço escolar: uma proposta de educação e saúde. Rio de Janeiro: Nugera, 2005.

DARIDO, S. C.; RANGEL, I. C. A.. Educação física na escola: implicações para a prática pedagógica. Rio de Janeiro: Guanabara Koogan, 2005.

FRANCO, M.. Análise de conteúdo. Brasília: Plano, 2003.

GIL, A. C.. Como elaborar projetos de pesquisa. 4 ed. São Paulo: Atlas, 2007.

GOMES, C. R.. A prática da professora e a construção das identidades de gênero em escola da Rede Municipal de Aracaju. Scientia Plena,São Cristóvão, v.3, n.5, p.229-237, 2007.

OLIVEIRA, G. K.. Aulas de educação física para turmas mistas ou separadas por sexo?: uma análise comparativa de aspectos motores e sociais. Dissertação (Mestrado em Educação Física) -Universidade Estadual de Campinas, Campinas, 1996.

PEREIRA, S. A. M.. O sexismo nas aulas de Educação Física: uma análise dos desenhos infantis e dos estereótipos de gênero nos jogos e brincadeiras. Tese (Doutorado em Educação Física) Universidade Gama Filho, Rio de Janeiro, 2004.

ROGER, S.. Uma dor sem tamanho. Veja, São Paulo, ed.2048, v.41, n.7, p.110-113, fev. 2008.

ROSISTOLATO, R. P. R.. Adolescência, sexualidade e saúde: intersecções entre as representações e as práticas dos professores que desenvolvem projetos de educação/orientação sexual na escola.. In: Seminário Internacional Fazendo Gênero, 7. Anais. Florianópolis, 2006.

VAITSMAN, J.. Gênero, Identidade, Casamento e Família na Sociedade Contemporânea. Rio de Janeiro: Relume Dumerá, 2001. 